\title{
Nickel (0) Complexes as Promising Chemosensors for Detecting the "Cork Taint" in Wine
}

\author{
Caterina Damiano, ${ }^{[a]}$ Daniela Intrieri, ${ }^{[a]}$ Paolo Sonzini, ${ }^{[a]}$ Silvia Rizzato, ${ }^{\left[{ }^{[a]}\right.}$ Corrado Di Natale, ${ }^{[b]}$ \\ Roberto Paolesse, ${ }^{[\mathrm{c}]}$ and Emma Gallo*[a]
}

2,4,6-Trichloroanisole (TCA) is well recognized as one of the most responsible molecules of cork taint, an organoleptic defect of wine which represents a serious problem for wine industries. Up to now, very few examples of TCA-biosensors have been developed and we report herein a promising nickel (0) complex that can be employed as chemosensor for the TCA detection in cork stoppers. Among the three $\mathrm{Ni}(0)$ complexes studied in this work, complex $\mathrm{Ni}(0)(\mathrm{BINAP})\left(\eta^{2}-\mathrm{PhCN}\right)$ (2) showed the best reactivity towards pure TCA affording the oxidative addition product $\mathbf{4}$ in four hours at room temperature. Compound $\mathbf{4}$ represents an appealing probe for the indirect quantification of
TCA due to the presence of the characteristic UV-adsorption band at $444 \mathrm{~nm}$. Statistical studies on real samples confirmed that the presence of TCA can be detected by employing UVVisible spectroscopy, as demonstrated by PCA analyses which allowed distinguishing TCA-contaminated samples from noncontaminated ones. Even if the present study has to be considered a preliminary approach for the realization of a chemosensor usable in real systems, the here reported $\mathrm{Ni}(0)$ based sensing procedure represents the first examples of TCA chemical detection.

\section{Introduction}

Color, flavor, and aromas are the best-known organoleptic properties of wine that have made it one of the most appreciate and consumed alcoholic beverage worldwide. ${ }^{[1]}$ The complex mixture of flavors and aromas, obtained using different grape varieties $^{[2]}$ and aging processes, ${ }^{[3]}$ constitutes a kind of fingerprint that allows identifying the type and quality of wine. The latter can be preserved by employing adequate storage conditions $^{[4]}$ of temperature and humidity and by using the appropriate packaging. ${ }^{[5]}$

The traditional configuration of glass bottles and cork-based stoppers ensures one of the best wine conservations thanks to the peculiar chemo-physical and mechanical properties of cork. $^{[6]}$ This low-cost, eco-compatible and recyclable material

[a] Dr. C. Damiano, Dr. D. Intrieri, P. Sonzini, Prof. S. Rizzato, Prof. E. Gallo Department of Chemistry

University of Milan

Via Golgi 19, 20133 Milan, Italy

E-mail:emma.gallo@unimi.it

https://sites.unimi.it/emmagallogroup/

[b] Prof. C. Di Natale

Department of Electronic Engineering

University of Roma Tor Vergata

Viale del Politecnico, 00133 Rome, Italy

[c] Prof. R. Paolesse

Department of Chemical Science and Technologies

University of Roma Tor Vergata

Via della Ricerca Scientifica 1, 00133 Rome, Italy

Supporting information for this article is available on the WWW under https://doi.org/10.1002/ejic.202101013

of (c) 2022 The Authors. European Journal of Inorganic Chemistry published by Wiley-VCH GmbH. This is an open access article under the terms of the Creative Commons Attribution Non-Commercial NoDerivs License, which permits use and distribution in any medium, provided the original work is properly cited, the use is non-commercial and no modifications or adaptations are made. shows high compressibility, flexibility and chemical inertness and its very low permeability to liquids and gases avoids leaks and gas exchanges ${ }^{[7]}$ with the external environment, which could damage the wine quality. It is important to note that the cork permeability, especially towards oxygen, ${ }^{[8]}$ can be modulated through specific treatments in order to allow a suitable control of the oxygenation process that is required for very aged wines. ${ }^{[3]}$ Despite all the above mentioned advantages, cork is partially responsible for the so-called "cork taint" ${ }^{\text {" }}{ }^{[9]}$ which represents a serious problem for wine industries.

Cork taint is an organoleptic defect of wine characterized by dusty, moldy and earthly aromas. ${ }^{[10]}$ The intensity of this imperfection is strongly related to the presence of volatile offflavor compounds, such as haloanisoles (Figure 1), ${ }^{[11]}$ which can be transferred from cork stoppers to wine after the bottling process. $^{[12]}$

Among all the off-flavor species involved in the cork taint, 2,4,6-trichloroanisole (TCA $)^{[12 b]}$ is well recognized as one of the most damaging due to its ability to suppress human olfactory

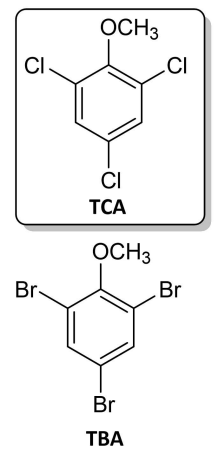<smiles>COc1ccc(Cl)cc1Cl</smiles><smiles>COc1c(Cl)cccc1OC(=O)O</smiles><smiles>COc1c(Cl)cc(Cl)c(Cl)c1Cl</smiles><smiles>COc1c(Cl)c(Cl)c(Cl)c(Cl)c1Cl</smiles>

Figure 1. Haloanisoles responsible for the cork taint. 
signal transduction. ${ }^{[13]}$ In fact, even if TCA can be present in extremely low concentrations, this molecule acts as an olfactory masking agent by reducing the perception of pleasant wine aromas and adding an unpleasant musty smell. Unfortunately, the problem related to the TCA presence cannot be easily solved because this compound derives from several sources ${ }^{[14]}$ such as contaminated grapes, water and air pollution, barrels, and cork stoppers.

To reduce the financial loss related to the presence of contaminated cork taint, winemakers random control cork stoppers in order to remove the TCA-containing ones and prevent the wine damage. Considering the concentration range in which TCA can be generally found $\left(\mathrm{ngL}^{-1}\right){ }^{[15]}$ extremely sensitive and selective analytical techniques are necessary for its determination. To achieve this purpose, numerous chromatographic-based methodologies have been developed ${ }^{[16]}$ such as gas chromatography-mass spectroscopy (GC-MS) analyses ${ }^{[15,17]}$ which require the sample pre-concentration or solid-phase microextraction (SPME). Even if these methods are very sensitive and efficient, the required equipment is notably expensive, especially for small producers.

For this reason, the scientific research is focusing on the development of valid alternatives based on rapid and disposable sensors. Up to now very few examples of TCA-sensors have been reported ${ }^{[18]}$ and they exploit cells, ${ }^{[19]}$ antibodies, $^{[20]}$ or combination of them to convert the biological response to TCA in electrical or optical signals, which can be employed to recognize it. Is important to underline that these biosensors are really promising both in terms of response and rapidity but, albeit some of them have been validated by chromatographic methods, their application to real samples has been limited due to the variety of parameters that can affect the biosensor response such as $\mathrm{pH}$, incubation time and interferant compounds derived from the cork stopper.

On the other hand, an interesting approach for the TCA detection could be based on specific chemical interactions between the analyte and opportunely designed chemosensors.

Aryl chlorides can be efficiently involved in oxidative addition reactions with phosphine-ligated nickel (0) complexes forming $\mathrm{Ni}$ (II) compounds, which are very reactive towards amines $^{[21]}$ or ketones. ${ }^{[22]}$ Thus, considering our knowledge on the synthesis of chemosensors for the detection of pollutants, ${ }^{[23]}$ we here report a nickel (0)-based procedure for the chemical sensing of TCA.

The described $\mathrm{Ni}(0)$ complexes efficiently react with the analyte through an oxidative addition reaction affording Ni (II) complexes, which show different adsorption spectra with respect to those of their precursors.

This study represents a very promising starting point for the development of colorimetric chemosensors for a cheap and rapid detection of TCA in polluted cork wine.

\section{Results and Discussion}

In order to design an efficient experimental protocol for the cork stopper analysis, we first analyzed the spectroscopic characteristics of TCA which, despite TCA is a well-known molecule, have not been adequately reported in literature.

The thermal stability of TCA in tetrahydrofuran (THF) up to $70^{\circ} \mathrm{C}$ indicated that THF can be efficiently employed as the testing solvent both at room and refluxing temperatures.

As reported in Figure 2, the UV-visible spectra acquired at different THF concentrations of TCA (from $1.00 \times 10^{-4}$ to $2.30 \times$ $10^{-3} \mathrm{M}$ ) showed a broad absorption band with a maximum at $291 \mathrm{~nm}$. This latter signal was employed for the construction of a calibration curve that allowed the calculation of the TCA molar extinction coefficient $\left(\varepsilon_{291 \mathrm{~nm}}=652.59 \mathrm{~cm}^{-1} \mathrm{M}^{-1}\right)$ and the so-called $L O D$ ( $L O D=$ limit of detection), which represents the minimum concentration of compound detectable by UV-visible spectroscopy. Collected data revealed the inefficiency of UVvisible spectroscopy as diagnostic technique for the direct determination of TCA in view of the calculated LOD $(1.25 \times$ $\left.10^{-4} \mathrm{M}\right)$ that exceeded the usual concentrations of TCA in real polluted cork stoppers $\left(1 \times 10^{-12} \mathrm{M}<[\mathrm{TCA}]>1 \times 10^{-11} \mathrm{M}\right)$.

On the other hand, UV-visible spectroscopy can be suitable for the indirect determination of TCA by reacting it with a chromophore showing a more intense UV-visible absorbance, which permits an easily detection of the so-formed reaction product.

To achieve this purpose, nickel (0) complexes 1-3 were synthesized in accordance to synthetic procedures already reported in literature ${ }^{[21,24]}$ through ligand exchange reactions and by using $\mathrm{Ni}(\mathrm{COD})_{2} \quad(\mathrm{COD}=1,5$-cyclooctadiene $)$ as the reactant species (Scheme 1 ).

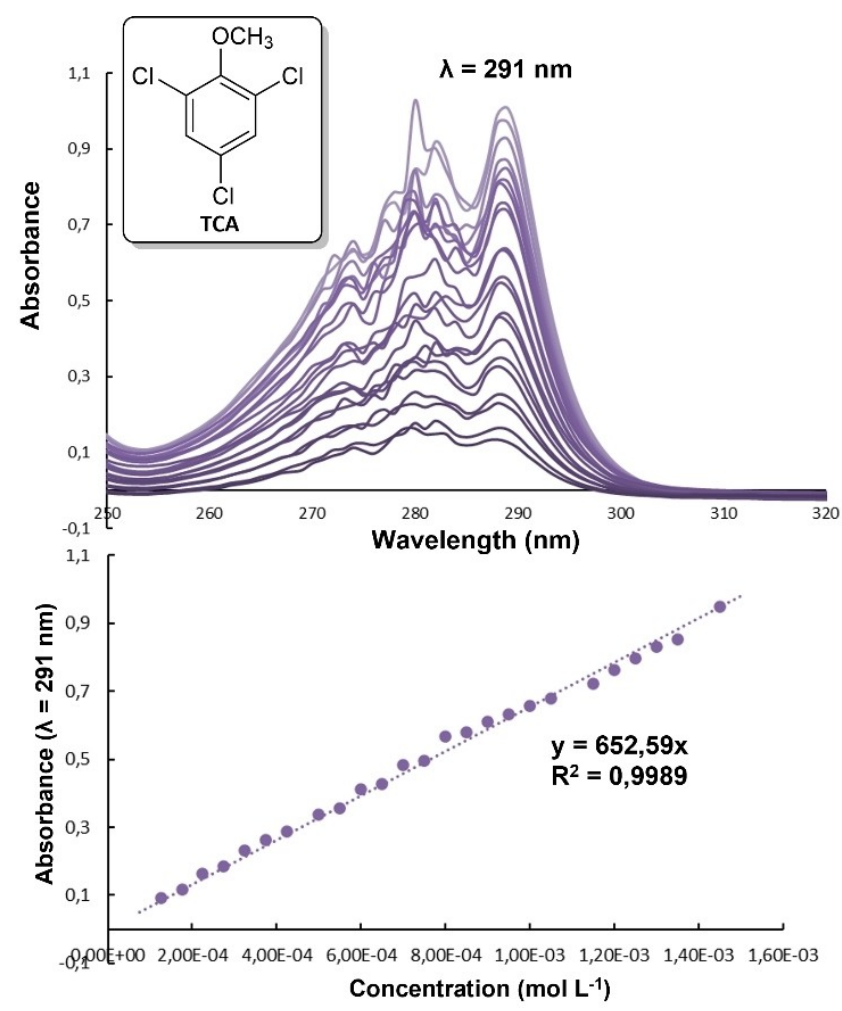

Figure 2. Absorption spectra of TCA and its calibration curve. 


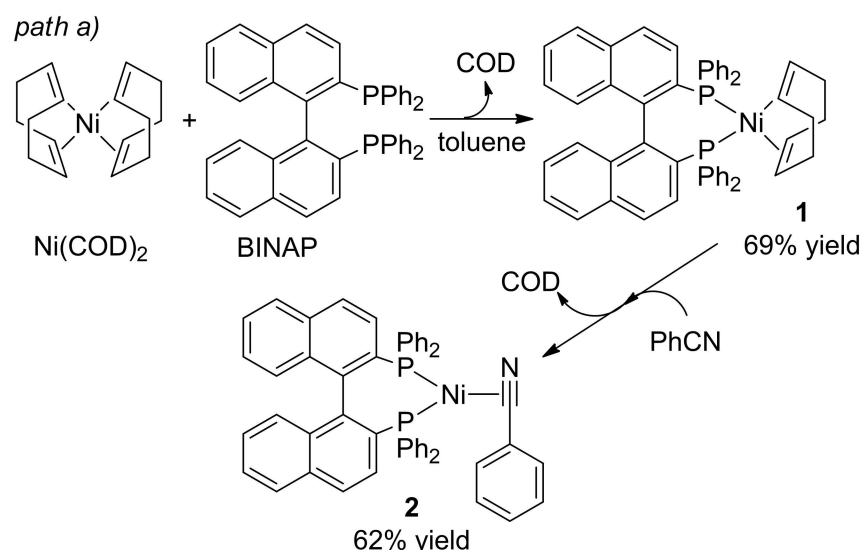

path b)

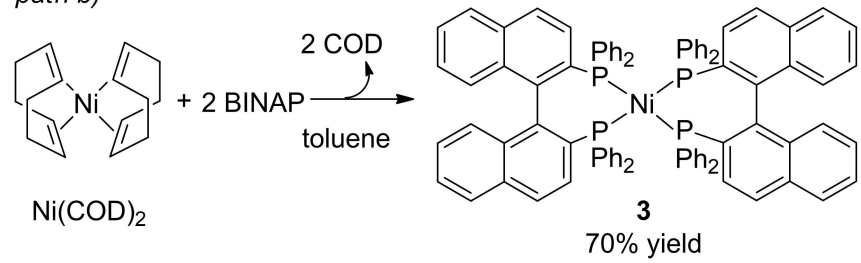

Scheme 1. Synthesis of nickel (0) complexes 1-3.

As showed in path a of Scheme 1, complex Ni(0)(BINAP)(COD) (1) was obtained in $69 \%$ yield by reacting equimolar amount of $\mathrm{Ni}(\mathrm{COD})_{2}$ and BINAP (BINAP $=2,2^{\prime}-$ bis(diphenylphosphino)-1,1'-binaphthyl) in toluene. Then, the addition of benzonitrile ( $\mathrm{PhCN}$ ) to the crude reaction mixture containing 1 afforded the desired product $\mathrm{Ni}(0)(\mathrm{BINAP})\left(\eta^{2}\right.$ PhCN) 2 in $62 \%$ global yield by the simple replacement of the COD ligand.

On the other hand, complex $\mathrm{Ni}(\mathrm{BINAP})_{2}$ (3) was achieved in $70 \%$ yield by reacting $\mathrm{Ni}(\mathrm{COD})_{2}$ with BINAP in $1: 2$ ratio (path $b$, Scheme 1) under the same experimental conditions which were employed for the synthesis of 1 .

All the complexes were isolated by filtration under inert atmosphere and fully characterized by ${ }^{1} \mathrm{H}$ and ${ }^{31} \mathrm{P}$ NMR as well as UV-visible spectroscopy.

In order to compare the reactivity of each complex and assess a possible role of the ligand, the so-obtained complexes 1-3 were tested in the oxidative addition reaction of TCA by using THF as the reaction solvent (Scheme 2).

Considering that two inequivalent $\mathrm{C}-\mathrm{Cl}$ bonds are present in the TCA molecule, two different Ni (II) complexes can be formed as a result of the oxidative addition. The cleavage of $\mathrm{C}-\mathrm{Cl}$ bonds in the ortho position with respect to the methoxy group can yield 4, while product 5 can be obtained when the $\mathrm{C}-\mathrm{Cl}$ bond in the para position is broken (Scheme 2).

The flash chromatography purification of the crude mixture of the three reactions employing 1, 2 or 3 starting nickel (0) complex, performed reacting 1-3 with a stochiometric amount of TCA $\left(1.32 \times 10^{--2} \mathrm{M}\right)$, revealed the presence of $\mathrm{Ni}$ (II) complex 4 as the sole product. The latter was formed according to previous mechanistic studies on the oxidative addition of aryl halides to phosphine-ligated nickel(0) complexes, which occurs preferentially to the ortho position of the aromatic ring by

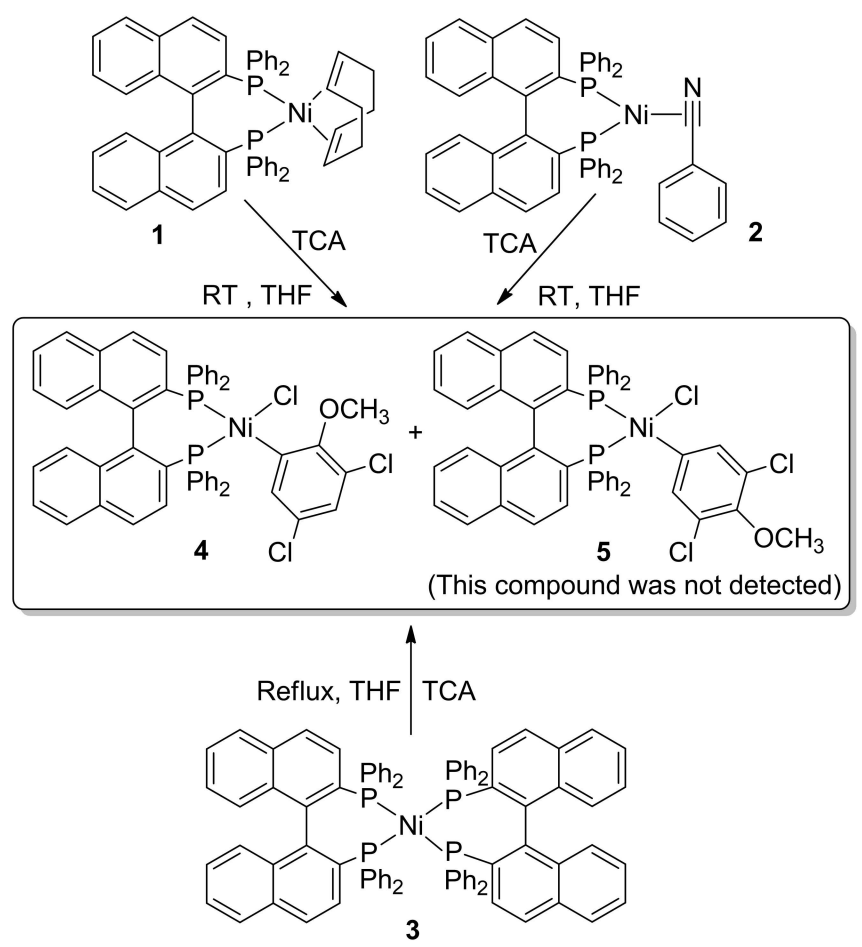

Scheme 2. Oxidative addition of complexes 1-3 and TCA.

following an $\mathrm{S}_{\mathrm{N}}$-Ar-Type oxidative addition in which a Meisenheimer-type complex acts as the transition state. ${ }^{[24 b]}$ When 1 or 2 complex was employed as the starting material, the complete conversion was achieved in 4 hours at room temperature, on the other hand, the consumption of complex 3 required 6 hours in refluxing THF. The different reactivity of these complexes can be due to the different nature of the ligands that are coordinated to the nickel center. The easier conversion of 1 and 2 into 4 can be attributed to the weaker linkage between the metal center and COD or PhCN ligands, which can be efficiently replaced by the TCA molecule. Conversely, the de-coordination of the more strongly bonded BINAP ligand in compound 3 required more severe experimental conditions.

Compound 4 was stable enough to be easily isolated in air and fully characterized by ${ }^{1} \mathrm{H}$ and ${ }^{31} \mathrm{P}$ NMR, mass spectroscopy and UV-visible. In addition, a preliminary X-ray diffraction structure of product $\mathbf{4}$ was obtained that, despite the low data quality, unambiguously confirm its molecular constitution and atom connectivity (Figure 3) (see SI for further details).

Even if all complexes efficiently reacted with TCA forming compound 4, the purification of reactions starting from 1 and 3 was not efficient and the desired compound was always contaminated by small number of COD and BINAP ligands, respectively. Thus, considering that the reaction performed better and under milder experimental conditions when 2 was used as starting material, the latter was chosen as the most promising candidate for the chemical sensing of TCA.

In order to evaluate if UV-visible spectroscopy should be an efficient signaling methodology for a real-time response, the 


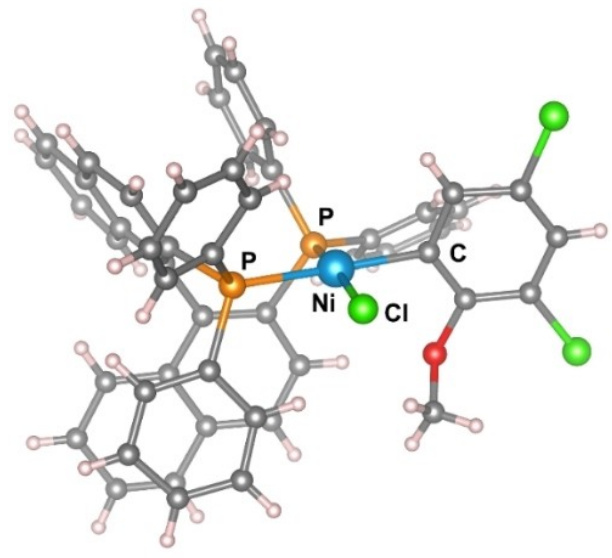

Figure 3. Schematic diagram of the molecular structure of compound $\mathrm{Ni}(\mathrm{BINAP})\left[\mathrm{C}_{6} \mathrm{H}_{2}\left(\mathrm{OCH}_{3}\right) \mathrm{Cl}_{2}\right] \mathrm{Cl} \cdot$ solv (4) showing the $\mathrm{Ni}-\mathrm{C}$ bond formed with the carbon in ortho position with respect to the methoxy group. Solvent molecule has been omitted for clarity. A directionality of the oxygen atom toward the metal centre can be observed.

adsorption spectra of the starting $\mathrm{Ni}(0)$ complex 2 and the $\mathrm{Ni}$ (II) product 4 were compared.

As reported in Figure 4, the two compounds presented very different spectra. Complex 2 displayed a broad adsorption spectrum with a poorly defined maximum at $591 \mathrm{~nm}$ that was selected for the construction of the calibration curve. Conversely, product 4 exhibited a distinctive spectrum with a maximum at $444 \mathrm{~nm}$, which was extremely useful to detect the formation of this compound and perform the indirect determination of TCA. Calibration curves built for both complexes revealed a higher molar extinction coefficient $\left(\varepsilon_{441 \mathrm{~nm}}=\right.$ $802.96 \mathrm{~cm}^{-1} \mathrm{M}^{-1}$ ) and a lower LOD value for product 4 (LOD = $\left.1.87 \times 10^{-5} \mathrm{M}\right)$ with respect to those of both the starting complex $2\left(\varepsilon_{591 \mathrm{~nm}}=368.29 \mathrm{~cm}^{-1} \mathrm{M}^{-1} ; \mathrm{LOD}=5.71 \times 10^{-4} \mathrm{M}\right)$ and the isolated TCA $\left(\varepsilon_{291 \mathrm{~nm}}=652.59 \mathrm{~cm}^{-1} \mathrm{M}^{-1}\right.$; LOD $\left.=1.25 \times 10^{-4} \mathrm{M}\right)$.

It should be noted that while the UV-visible analysis of compound $\mathbf{4}$ was performed in air thanks to its high stability, complex $\mathbf{2}$ was analyzed under inert atmosphere because its degradation in presence of oxygen caused the decrease of its broad absorption band at $591 \mathrm{~nm}$ (see SI for more details).

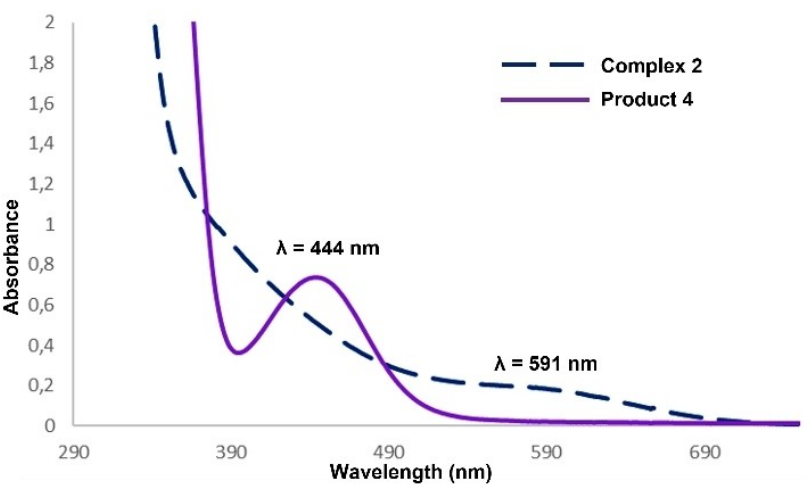

Figure 4. Overlapped UV-visible spectra of compounds 2 and $\mathbf{4}$.
Considering the peculiar UV-visible adsorption band of the product 4, its formation was followed by measuring the increase of the absorption band at $444 \mathrm{~nm}$. Complex 2 was stoichiometrically reacted with TCA under inert atmosphere at room temperature and the reaction mixture was analyzed at different reaction times. To better detect the absorption band of 4 at $444 \mathrm{~nm}$, the analyzed reaction mixture was opportunely diluted with THF and exposed to air to reduce the broad adsorption band of the starting complex 2 (vide supra). The progressive formation of compound 4 was observed and acquired data revealed that the product is almost totally formed after one hour (49\% versus $53 \%$, which was registered after 4 hours). These data suggested that the oxidative addition of TCA to complex 2, forming 4, can be efficiently carried out in only one hour (see SI for more details).

In view of the good reactivity of 2 towards TCA and the possibility to clearly detect the formation of complex 4, some preliminary tests employing complex 2 for the TCA sensing in real systems were performed.

Both TCA-contaminated and non-contaminated cork stoppers were finely chopped and refluxed for 16 hours in dried THF under nitrogen atmosphere in order to extract TCA together with all the other compounds, which are contained in corks and can interfere with the sensing process. The excess of solid was removed by filtration and the obtained solutions were opportunely diluted and analyzed by UV-visible spectroscopy under inert atmosphere.

Considering that in a real system TCA would be in much lower concentrations than the chemosensor, complex 2 was added to the extracted solutions in a large excess and reacted for 16 hours at room temperature. Unfortunately, the excess of complex $\mathbf{2}$ did not allow detecting the formation of $\mathbf{4}$ because the characteristic band at $444 \mathrm{~nm}$ was covered by the broad spectrum of unreacted 2 . The resulting spectrum was quite similar to that obtained by adding 2 to the solution obtained by extracting non-contaminated samples.

The characteristic signal of $\mathbf{4}$ was not observed even after the addition of a known quantity of pure TCA (corresponding to the minimum LOD previously defined) to the extracted solution of contaminated stoppers to confirm that the broad adsorption band of unreacted complex 2 covered the region of interest.

To ascertain the capability of the method to detect contaminated corks, three groups of samples were prepared from tainted and untainted stoppers, which were provided by a cork producer. The concentration of TCA in contaminated corks, evaluated by the producer, was in the range $37 \pm 18 \mathrm{ng} / \mathrm{g}$. Stoppers were treated with the methodology described above in order to prepare samples of TCA-contaminated (a) and noncontaminated (b) cork stoppers and the $\mathbf{a} / \mathbf{b}$ mixture (c).

Figure $5 \mathrm{~A}$ shows all collected spectra. A simple visual inspection of the spectra did not allow a clear identification of each group of stoppers. However, a standard processing of the ensemble of spectra, made of spectra filtering and principal component analysis, enabled the identification of corks according to the TCA level content. Figure 5B shows the spectra processed by a third order Savitsky-Golay filter and normalized in the $0-1$ range. ${ }^{[25]}$ 

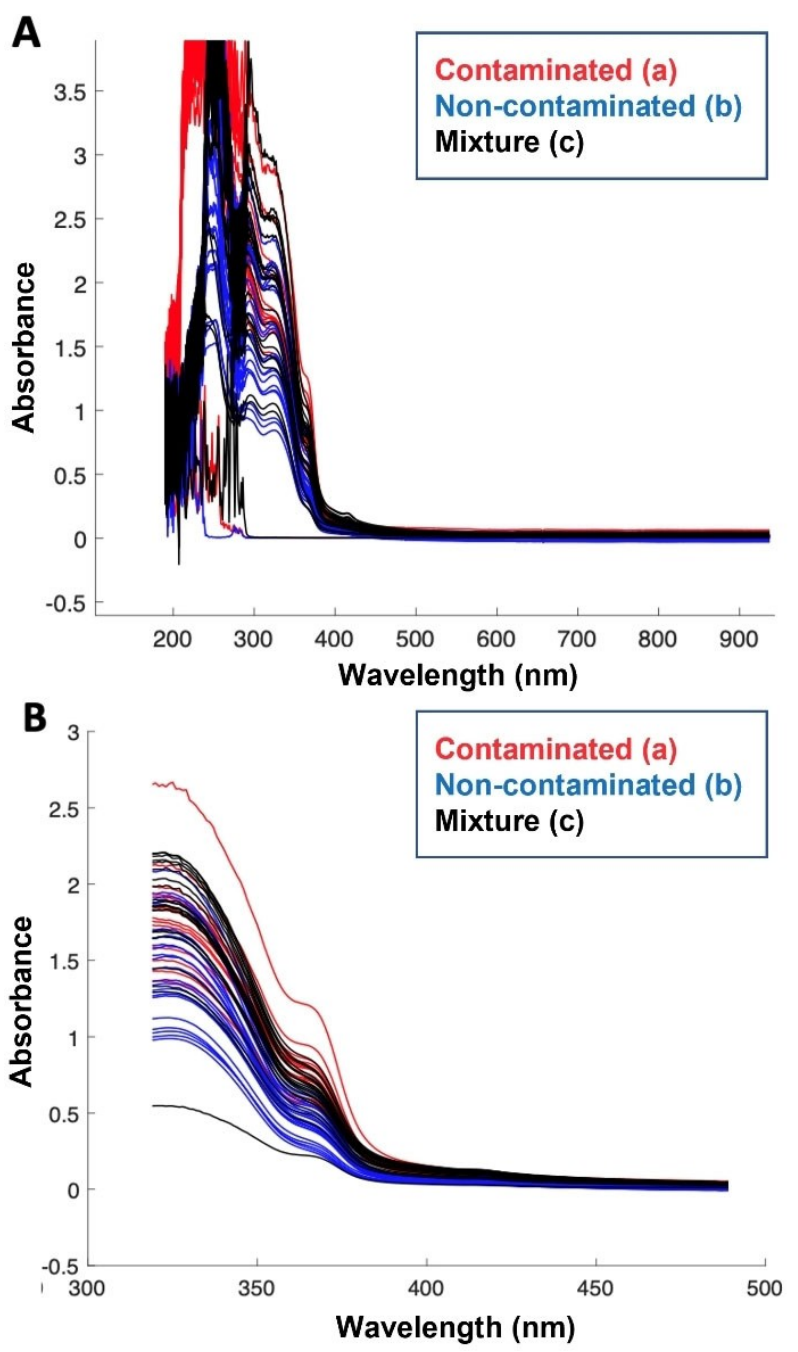

Figure 5. A: unprocessed and B: processed UV-visible spectra. The plot has been restricted to the interval $320-490 \mathrm{~nm}$.

Principal component analysis (PCA) removed the correlation between the spectral wavelengths putting into evidence the uncorrelated information contained in the spectra. ${ }^{[26]}$ PCA has been calculated on zero centered spectra. The first two principal components exploited more than $98 \%$ of the total variance. Figure $6 \mathrm{~A}$ shows the scores plot in the plane of the first two principal components. A clear separation between the three groups was observed long the first principal component where the three groups are clustered according to the growing TCA content. The second principal component added little to the identification of contaminated corks, however it evidenced the group of $\mathbf{a} / \mathbf{b}$ mixture respect to the others. This behaviour evidenced the potentialities of the proposed approach for the quantification of TCA content. Figure $6 \mathrm{~B}$ shows the first and second loadings of the PCA model. The loadings express the contribution of each wavelength to the plot of Figure $6 \mathrm{~A}$. The first principal component was positive for high TCA content and the largest contribution to high TCA detection was achieved at $\lambda=387 \mathrm{~nm}$ (samples a). On the other hand, the
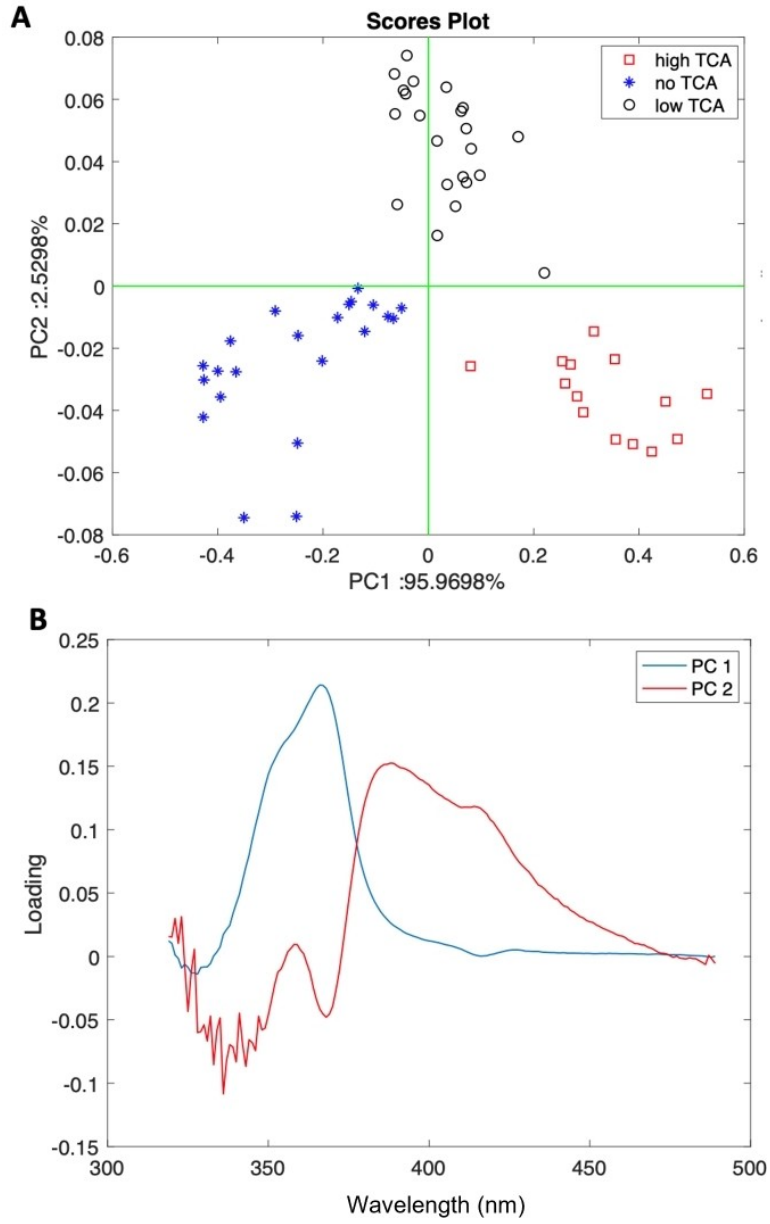

Figure 6. Principal component analysis (PCA) of pre-processed spectra. A: scores plot and B: spectral loadings.

absorbance $\lambda=366 \mathrm{~nm}$ was the most responsible of the detection of low-level TCA contaminated corks (samples c). PCA highlighted those wavelengths characterized by the largest variability among the samples rejecting the spectral features common to all samples.

\section{Conclusion}

We reported a very promising nickel (0)-based procedure for detecting "cork taint" of wine. Three Ni (0) complexes were synthesized and tested in the oxidative addition with pure TCA. The best results were achieved by employing complex 2 that efficiently reacted with the target molecule by forming the oxidative addition product 4 , whose molecular structure was confirmed by single crystal $\mathrm{X}$-ray diffraction. The distinctive adsorption of 4 at $444 \mathrm{~nm}$ resulted to be a very interesting probe which can be employed for the indirect determination of TCA. In this paper a qualitative experiment has been carried out to prove the feasibility of cork contaminated detection. In this condition, PCA is a suitable algorithm to demonstrate that the spectra correctly identify three groups of corks: contaminated, 
non-contaminated and a mixture of those. On the other hand, other algorithms (e.g. Partial Least Squares) are available for quantitative analyses. The analytical characterization of the proposed method would require an independent measurement of TCA on real tainted corks. Such investigation, which will be carried out in a near future, is beyond the scopes of this proofof-principle paper.

Even if the application of $\mathbf{2}$ to real systems needs further investigations, this study represents a very encouraging starting point for the development of a cheap chemosensor applicable for the TCA quantification. To achieve this purpose, future studies will be devoted to modifying complex $\mathbf{2}$ in order to introduce functional groups which amplify the signal transduction and allow the TCA detection and quantification in polluted cork stoppers. Furthermore, due to the large sensitivity of $\mathrm{Ni}(0)$ complexes to oxygen, any future implementation of the method should be carried out under controlled atmosphere.

\section{Experimental Section}

\section{General}

Unless otherwise specified, all the reactions were carried out under nitrogen atmosphere employing standard Schlenk techniques and magnetic stirring. THF was distilled over sodium and benzophenone and kept under nitrogen. Toluene and pentane were distilled over sodium and kept under nitrogen. Benzonitrile was dried over $\mathrm{MgSO}_{4}$ and kept under nitrogen. $\mathrm{Ni}(0)$ complexes 1-3 were synthesized by methods reported in literature. ${ }^{[21-22,24 b]}$ All the other starting materials were commercial products used as received. NMR spectra were recorded at room temperature either on a Bruker Avance $300-D R X$, operating at $300 \mathrm{MHz}$ for ${ }^{1} \mathrm{H}$ and at $75 \mathrm{MHz}$ for ${ }^{13} \mathrm{C}$, or on a Bruker Avance $400-\mathrm{DRX}$ spectrometers, operating at $400 \mathrm{MHz}$ for ${ }^{1} \mathrm{H}$, at $100 \mathrm{MHz}$ for ${ }^{13} \mathrm{C}$ and at $121 \mathrm{MHz}$ for ${ }^{31} \mathrm{P}$. Chemical shifts (ppm) are reported relative to TMS. The ${ }^{1} \mathrm{H}$ NMR signals of the compounds described in the following were attributed by 2D NMR techniques. Assignments of the resonances in ${ }^{13} \mathrm{C}$ NMR were made by using the APT pulse sequence, HSQC and HMBC techniques. UVvisible spectra were recorded on an Agilent $8453 \mathrm{E}$ instrument. Elemental analyses and mass spectra were recorded in the analytical laboratories of Milan University.

\section{Synthesis of product 4 through oxidative addition of TCA to complex 2}

2,4,6-Trichloroanisole (TCA) $(19.0 \mathrm{mg}, 0.09 \mathrm{mmol})$ and $\left[\mathrm{Ni}(\mathrm{BINAP})\left(\eta^{2}-\right.\right.$ $\mathrm{PhCN})]$ (2) $(80.0 \mathrm{mg}, 0.10 \mathrm{mmol})$ were dissolved in $5 \mathrm{~mL}$ of dry THF and the mixture was stirred for 4 hours at room temperature until the complete consumption of the starting complex 2 was observed by TLC analyses $\left(\mathrm{SiO}_{2}, n\right.$-hexane/ethyl acetate $\left.=9: 1\right)$. During the reaction the color of the solution changed from yellow to orange and an orange powder precipitated. The crude precipitate was collected in a filter and purified by flash-chromatography $\left(\mathrm{SiO}_{2}, n\right.$ hexane/ethyl acetate $=9: 1)$ affording product 4 (53\% yield). Orange-red crystals were obtained by slowly adding $n$-hexane to a THF solution of complex 4. ${ }^{1} \mathrm{H}$ NMR $\left(300 \mathrm{MHz}, \mathrm{C}_{6} \mathrm{D}_{6}\right) \delta: 9.03(\mathrm{t}, \mathrm{J}=$ $9.5 \mathrm{~Hz}, 1 \mathrm{H}), 8.42(\mathrm{t}, J=9.5 \mathrm{~Hz}, 1 \mathrm{H}), 8.30-8.15(\mathrm{~m}, 3 \mathrm{H}), 7.93-7.82(\mathrm{~m}$, $3 \mathrm{H}), 7.52-7.40(\mathrm{~m}, 2 \mathrm{H}), 7.32-6.86(\mathrm{~m}, 12 \mathrm{H}), 6.84-6.68(\mathrm{~m}, 4 \mathrm{H}), 6.59$ (s, 2 $\left.\mathrm{H}_{\text {anisole }}\right), 6.52-6.37(\mathrm{~m}, 4 \mathrm{H}), 6.35-6.19(\mathrm{~m}, 2 \mathrm{H}), 4.59 \mathrm{ppm}\left(\mathrm{s}, 3 \mathrm{H}_{\text {оме }}\right)$. ${ }^{31}$ P NMR (121 MHz, $\left.\mathrm{C}_{6} \mathrm{D}_{6}\right)$ \&: 33.51 (dd, $\left.J=36.2,10.6 \mathrm{~Hz}\right), 27.44$ (s), $19.22(d, J=36.2 \mathrm{~Hz}), 16.90(\mathrm{~d}, J=36.5 \mathrm{~Hz}) .{ }^{13} \mathrm{C}$ NMR $(100 \mathrm{MHz}$,
$\left.\mathrm{CDCl}_{3}\right)$ $\delta: 136.26,136.14,135.83,135.69,135.56,135.23,134.37$, 133.82, 133.09, 132.86, 132.78, 130.77, 130.25, 127.00, 124.42, $60.25 \mathrm{ppm}$. Elemental Analysis calcd. for $\left(\mathrm{C}_{51} \mathrm{H}_{37} \mathrm{Cl}_{3} \mathrm{NiOP}_{2}\right): \mathrm{C}(68.61)$, $\mathrm{H}$ (4.18); found: $\mathrm{C}$ (68.31), H (4.58). LR-MS (ESI): $\mathrm{m} / \mathrm{z}\left(\mathrm{C}_{51} \mathrm{H}_{37} \mathrm{Cl}_{3} \mathrm{NiOP}_{2}\right)$ calcd 890.07 , found $857.15[\mathrm{M}+2 \mathrm{H}-\mathrm{Cl}]$. UV-Vis $\lambda_{\max }(\mathrm{DCM}) / \mathrm{nm}$ (log $\varepsilon): 444(2.90)$.

\section{Extraction from crock stoppers and oxidative addition}

Method A: Non-contaminated cork stoppers $(6.00 \mathrm{~g})$ were finely chopped and transferred in a Schlenk flask. $70 \mathrm{~mL}$ of THF were added and the mixture was refluxed for 16 hours. Then, the solid was filtered off and the obtained clear liquid was kept under nitrogen atmosphere. The solution was diluted $1: 25$ and the [Ni(BINAP) $\left.\left(\eta^{2}-\mathrm{PhCN}\right)\right](2)(28.0 \mathrm{mg}, 0.035 \mathrm{mmol})$ was added. The soobtained mixture was stirred for 16 hours at room temperature. Then, the solution was analyzed via UV-visible spectroscopy under nitrogen atmosphere, exposed to air and analyzed again. Method $B$ : the procedure illustrated for method $A$ was followed employing TCA-contaminated stoppers. Method C: the procedure illustrated for method B was followed adding TCA $(0.62 \mu \mathrm{mol})$ to the reaction mixture.

\section{Acknowledgements}

C.D. and E.G. thank Università degli Studi di Milano for PSR 2019 financed project "Catalytic strategies for the synthesis of high added-value molecules from bio-based starting material". Open Access Funding provided by Universita degli Studi di Milano within the CRUI-CARE Agreement.

\section{Conflict of Interest}

The authors declare no conflict of interest.

\section{Data Availability Statement}

The data that support the findings of this study are available from the corresponding author upon reasonable request.

Keywords: Nickel · Oxidative addition · Sensing $\cdot$ TCA · Wine

[1] M. C. Cravero, M. Laureati, S. Spinelli, F. Bonello, E. Monteleone, C. Proserpio, M. R. Lottero, E. Pagliarini, C. Dinnella, Food 2020, 9, 1131.

[2] a) V. Ferreira, R. Lopez, Biomol. Eng. 2019, 9, 818; b) J. Lin, M. Massonnet, D. Cantu, Hortic. Res. 2019, 6, 81.

[3] J. Echave, M. Barral, M. Fraga-Corral, M. A. Prieto, J. Simal-Gandara, Molecules 2021, 26, 713.

[4] S. Agriopoulou, E. Stamatelopoulou, EC Nutrition 2017, 8, 93-98.

[5] M. A. Silva, M. Julien, M. Jourdes, P.-L. Teissedre, Eur. Food Res. Technol. 2011, 233, 905-914.

[6] V. Oliveira, H. Pereira, In Chemistry and Biochemistry of Winemaking, Wine Stabilization and Aging, IntechOpen, London, UK, 2020.

[7] K. Crouvisier-Urion, J.-P. Bellat, R. D. Gougeon, T. Karbowiak, Trends Food Sci. Technol. 2018, 78, 255-269.

[8] P. Lopes, C. Saucier, P.-L. Teissedre, Y. Glories, J. Agric. Food Chem. 2007 55, 5167-5170.

[9] A. Tarasov, D. Rauhut, R. Jung, Talanta 2017, 175, 82-92. 
[10] M. C. Cravero, Beverages 2020, 6, 41.

[11] A. Peña-Neira, B. Fernández de Simón, M. C. García-Vallejo, T. Hernández, E. Cadahía, J. A. Suarez, Eur. Food Res. Technol. 2000, 211, 257-261.

[12] a) M. A. Sefton, R. F. Simpson, Aust. J. Grape Wine Res. 2005, 11, 226240; b) D. L. Capone, G. K. Skouroumounis, M. A. Sefton, Aust. J. Grape Wine Res. 2002, 8, 196-199.

[13] H. Takeuchi, H. Kato, T. Kurahashi, PNAS 2013, 110, 16235-16240.

[14] R. F. Simpson, M. A. Sefton, Aust. J. Grape Wine Res. 2007, 13, 106-116.

[15] P. Jové, A. Pareras, R. De Nadal, M. Verdum, J. Mass Spectrom. 2021, 56, e4728.

[16] R. M. Callejón, C. Ubeda, R. Ríos-Reina, M. L. Morales, A. M. Troncoso, J. Chromatogr. A 2016, 1428, 72-85.

[17] a) R. Alzaga, L. Ortiz, F. Sánchez-Baeza, M.-P. Marco, J. M. Bayona, J. Agric. Food Chem. 2003, 51, 3509-3514; b) S. Jönsson, J. Hagberg, B. van Bavel, J. Agric. Food Chem. 2008, 56, 4962-4967; c) A. R. Fontana, S. H. Patil, K. Banerjee, J. C. Altamirano, J. Agric. Food Chem. 2010, 58, 4576-4581; d) S. H. Patil, K. Banerjee, S. C. Utture, A. R. Fontana, J. C. Altamirano, D. P. Oulkar, S. S. Wagh, S. Dasgupta, S. B. Patil, M. R. Jadhav, B. R. Ugare, P. G. Adsule, M. B. Deshmukh, Food Chem. 2011, 124, 17341740; e) I. Márquez-Sillero, S. Cárdenas, M. Valcárcel, J. Chromatogr. A 2011, 1218, 7574-7580; f) P. Slabizki, C. Legrum, P. Wegmann-Herr, C. Fischer, H.-G. Schmarr, Eur. Food Res. Technol. 2016, 242, 977-986.

[18] S. Mavrikou, S. Kintzios, Beverages 2018, 4, 24.
[19] a) V. Varelas, N. Sanvicens, M.-P. Marco, S. Kintzios, Talanta 2011, 84, 936-940; b) T. Apostolou, N. Pascual, M.-P. Marco, A. Moschos, A. Petropoulos, G. Kaltsas, S. Kintzios, Talanta 2014, 125, 336-340.

[20] a) N. Sanvicens, F. Sánchez-Baeza, M.-P. Marco, J. Agric. Food Chem. 2003, 51, 3924-3931; b) E. Moore, M. Pravda, G. G. Guilbault, Anal. Chim. Acta 2003, 484, 15-24; c) M. V. Duarte, P. Lozano-Sanchez, I. Katakis, Biosens. Bioelectron. 2009, 24, 2205-2210.

[21] S. Ge, R. A. Green, J. F. Hartwig, J. Am. Chem. Soc. 2014, 136, 1617-1627.

[22] S. Ge, J. F. Hartwig, J. Am. Chem. Soc. 2011, 133, 16330-16333.

[23] D. Intrieri, C. Damiano, S. Rizzato, R. Paolesse, M. Venanzi, D. Monti, M. Savioli, M. Stefanelli, E. Gallo, New J. Chem. 2018, 42, 15778-15783.

[24] a) A. L. Clevenger, R. M. Stolley, N. D. Staudaher, N. Al, A. L. Rheingold, R. T. Vanderlinder, J. Louie, Organometallics 2018, 37, 3259-3268; b) M. E. Greaves, E. L. B. Johnson Humphrey, D. J. Nelson, Catal. Sci. Technol. 2021, 11, 2980-2996.

[25] W. Schafer, IEEE Signal Process 2011, 28, 111-117.

[26] I. Jolliffee, Principal Component Analysis, second edition, 2002, Springer US, New York (USA).

Manuscript received: November 25, 2021

Revised manuscript received: January 18, 2022 
The oxidative addition of 2,4,6-trichloroanisole (TCA) to $\mathrm{Ni}$ (0)(BINAP) $\left(\eta^{2}-\mathrm{PhCN}\right)(2)$ represents a valuable procedure for the TCA detection in wine-stoppers due to the formation of the Ni (II) complex (4), showing a distinguishing UVvisible spectrum. Product 4 was characterized by $\mathrm{X}$-ray analysis and allowed the indirect TCA determination in polluted corks as also demonstrated by the principal component analysis (PCA) on real samples.

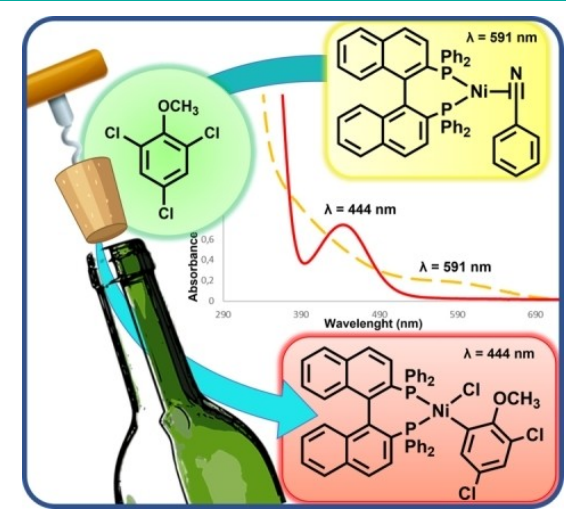

Dr. C. Damiano, Dr. D. Intrieri, $P$. Sonzini, Prof. S. Rizzato, Prof. C. Di Natale, Prof. R. Paolesse, Prof. E. Gallo*

$1-8$

Nickel (0) Complexes as Promising Chemosensors for Detecting the "Cork Taint" in Wine 